\title{
La Construcción Simbólica de la Cruz Cristiana: Un Emblema de la Víctima Sacrificial
}

DANIELA PAZ JARA LEIVA

\section{El símbolo de la crucifixión}

Uno de los símbolos centrales del cristianismo -o más acertadamente, los cristianismos- es la imagen de un hombre crucificado, la que corresponde al Mesías o Salvador -también denominado el Cristo- en el cumplimiento de su destino (aquello que estaba en las escrituras) y próximo a su realización (la Vida Eterna).

Un hombre crucificado se ha transformado en el rostro de una religiosidad, al que le ha sido asignado un carácter abiertamente polisémico: en ciertos momentos ha sido el emblema de una política de colonización cultural -también denominada evangelización-, el escudo de una caza de brujas o la inspiración de una teología de la liberación y lucha por la justicia social.

En el relato bíblico de la crucifixión de Jesús de Nazareth (denominado el Cristo) y en la abundante producción pictórica, literaria, dramática, mítica y- a partir del siglo XX-cinematográfica que ha sido inspirada por el relato cristiano, aquello que predomina es el dolor: se trata de un hombre sufriendo un tipo de tortura propio de su época. Desde una perspectiva sociológica, la crucifixión pareciera responder a un acto sacrificial. Éste constituye una de las prácticas más antiguas de la humanidad, vinculada muchas veces con formas primitivas de religiosidad, cuyo fin último es la canalización de la violencia sobre un individuo, lo que permite la sobrevivencia de la comunidad ${ }^{1}$.

Resulta muy curioso que en el relato del nacimiento, vida pública, muerte y resurrección de Jesús que hacen los evangelistas ${ }^{2}$, no sea mencionada la noción de sacrificio $^{3}$, y quien ha sido crucificado no sea considerado -al menos en lo explícitouna ofrenda sacrificial.

1 Girard, René: "La violencia y lo sagrado".

2 Mateo, Marcos, Lucas y Juan.

3 Ver especialmente los anuncios de la Pasión, en el Nuevo Testamento. 
En el Antiguo Testamento, se hace referencia a un pecado original que ha expulsado al hombre del Paraíso, condenándolo. El sacrificio -desde la interpretación religiosa- tiene como objeto la liberación de alguna culpa o pecado, es decir, la purificación. De esta manera, la crucifixión de un hombre que dice ser Hijo de Dios parece convertirlo en una ofrenda para calmar la ira de un dios.

Cuando se observa la cruz, sin ser necesariamente creyente, se decodifica un significado que supera ampliamente el acto de tortura. Se está frente a uno de los emblemas de la civilización occidental -con más o menos fuerza- a partir del siglo III: se trata de una ética, una narración sobre lo humano y su relación con la divinidad, una pertenencia social (como modo de distinción) a una comunidad. Lo que nos interesa en este caso es precisamente este fenómeno de ocultamiento o sublimación del carácter sacrificial ${ }^{4}$ y penal de la crucifixión. La cruz cristiana no habla de sí misma (la tortura), sino que habla por sí misma, constituyéndose en un discurso societal.

\section{Un breve recuento del acto previo al sacrificio: la detención de la víctima en Jerusalén}

Para reflexionar sobre dicho proceso de ocultamiento, resulta interesante, si no necesario, revisar los antecedentes mítico-literarios -y sólo en algunos aspectos, históricos- de la crucifixión.

Un hecho crucial para el cumplimiento del mandato que se le atribuye a Jesús de Nazareth dentro de la construcción cristiana, ocurre en la ciudad santa, Jerusalén, lugar donde habría de ser condenado a la crucifixión. Fue en esta ciudad donde habría de encontrar mayor hostilidad y resistencia a su prédica y donde estaba físicamente, además, el procurador romano, máximo representante del poder imperial.

De acuerdo a los evangelistas, uno de los apóstoles (Judas) traiciona a Jesús, y revela al Sanedrín el lugar de su retiro nocturno. Una vez conducido a éste, Jesús se declara a sí mismo como el Mesías, razón por la cual sacerdotes y escribas le condenan y conducen hacia el procurador Poncio Pilatos.

La apropiación simbólica de la noción de Mesías -lo que da lugar a la monopolización del concepto y la legitimidad para su distribución (o uso)- es probablemente la mayor causa de disputa entre Jesús (y sus seguidores) y el Sanedrín (una especie de tribunal religioso). Es interesante recurrir a la teoría de los campos sociales $^{5}$ : el Mesías, para serlo, requiere ser reconocido-tarde o temprano-por su grupo social; es Mesías en función del rol que le es asignado. Aquí ocupa un lugar impor-

4 Específicamente desde la perspectiva sociológica: sobre la función social del sacrificio.

5 De acuerdo a Pierre Bourdieu, el espacio social puede ser entendido como un campo donde los actores, definidos por sus posiciones, disputan la valorización o el posicionamiento de sus capitales. 
tante el proceso de legitimación del discurso, que lleva a conceder - o no- dicho título a un sujeto, por parte de una comunidad. En este caso, el poder de nominación como Mesías actuaba en el orden de los reconocimientos, valorizando un nuevo orden (cristianismo) en oposición a un viejo orden (tradición judía). Al interior de la comunidad judía tenía lugar una disputa de un bien lingüístico -con connotaciones políticas (el destino de Israel)- que operaba como nombramiento.

Jesús es interrogado por Pilatos, quien no le encuentra culpable. Frente a la insistencia de los judíos, expone el caso ante las turbas expectantes. Finalmente, Jesús es crucificado. En este instante se transforma, por un lado, en chivo expiatorio (desde una perspectiva social) ${ }^{6}$, y en víctima sacrificial, por otro.

\section{René Girard: hacia una teorización sociológica del sacrificio}

Para acercarse al problema de la cruz como símbolo sacrificial resulta necesario referirse al desarrollo teórico que respecto a la función social del sacrificio ha llevado a cabo René Girard, quien busca establecer una relación entre la violencia y lo sagrado.

Girard entiende el fenómeno del sacrificio como íntimamente ligado con la violencia y es en este vínculo donde radicaría su función social. La violencia sin mecanismos de regulación constituye un peligro para la sobrevivencia de los miembros de una comunidad. Sin embargo, en su carácter irracional, la violencia como deseo siempre está en condición de encontrar víctimas de recambio. En caso de no poder saciar el iracundo su ira a través del objeto causal, éste lo sustituye sin alteración con otro objeto ${ }^{7}$. Por tanto, más que el ajusticiamiento, en el fondo del deseo de violencia prima la necesidad de expresión, manifestación y en última instancia, liberación. En la sustitución se encuentra un vehículo para aquello.

El sacrificio, por su parte, también estaría basado en un proceso de sustitución de la víctima: Girard y un sector de la etnología moderna proponen que el sacrificio desvía la violencia de algunos seres a los que se intenta proteger hacia otros seres cuya muerte tiene una importancia menor. De esta manera, la violencia original se dirige hacia la víctima sacrificial, que sustituye a un objeto de mayor valor (la comu-

6 Decimos que es un chivo expiatorio porque corresponde a aquella figura considerada como culpable por una muchedumbre: se trata de una asignación colectiva. De esta manera, el culpable es utilizado por la multitud para expiar sus corrientes de desintegración y anomia. La comunidad se restablece una vez que señala a la víctima, quien suele ocupar una posición marginal en el espacio social. Su extinción no pone nada en peligro" Ver Girrad, René: "El Chivo expiatorio".

7 "Sustituye de repente la criatura que excitaba su furor por otra que carece de todo titulo especial para atraer las iras del violento, salvo el hecho de que es vulnerable y está al alcance de su mano". Girard, René: "La violencia y lo sagrado", pg. 10. 
nidad). Es importante referir que junto a la sustitución opera un principio de ocultamiento: se requiere ignorar este mecanismo (que sea inconciente, en términos de la psicología moderna). El velo que cae sobre el sacrificio es condición de su eficacia ${ }^{8}$. Es así como podemos entender el sacrificio como una función social preventiva de la violencia ${ }^{9}$, vinculada con la sobrevivencia y la reproducción de la sociedad.

Girard elabora un marco analítico alternativo al ofrecido por la teología del sacrificio. Esta última se explica a partir de su autosignificación: la reclamación de una divinidad que reclama a sus víctimas, o la posibilidad de mediar entre el ser humano y la divinidad mediante un ofrecimiento. El sacrificio es desde aquí la destrucción de un bien, o su renuncia, en honor a una divinidad. ${ }^{10}$

\section{La cruz: historia y símbolo}

Una vez que ya hemos revisado la noción sociológica de sacrificio, podemos abordar el segundo problema de esta formulación: el ocultamiento de un significado (la tortura) mediante la visibilización de otro (el relato cristiano).

Podemos plantear que existen -al menos- dos dimensiones de la cruz: una dimensión histórica y otra simbólica. La primera de estas dimensiones tiene que ver con el uso y significación social que se le daba a la cruz en el momento histórico al que estamos haciendo referencia (alrededor del año 30 d.c). Nos ubicamos en tiempos donde supuestamente existió Jesús de Nazareth (al menos como construcción de carácter mítico, proclamado en las fuentes ${ }^{11}$ ).

Jesús fue condenado a la crucifixión bajo una sentencia romana; no fue lapidado como lo eran los transgresores de la ley judía. Existen distintas versiones sobre la responsabilidad central de su condena, si acaso ésta recae en el Sanedrín (mundo judío) o en el Imperio (mundo romano). ${ }^{12}$

La crucifixión era uno de los más crueles instrumentos de tortura de los que disponía el Imperio Romano. El instrumento antecesor a la cruz era una estaca vertical a la cual se ataba al condenado y se le dejaba ahí hasta morir; de aquí deri-

8 Curiosamente, Girard hace referencia a una bibliografia china donde se reconocería explícitamente la función socialmente apaciguadora del sacrificio.

9 Para Girard, lo religioso es fundamentalmente preventivo.

10 El sacrificio tiene como fin la purificación, es decir, la liberación de alguna culpa o pecado, o la consagración, y que tiene como objeto persuadir a la divinidad para que conceda su garantía a la persona o cosa consagrada.

11 Los cuatro evangelistas ya citados, sobre cuya existencia hay una gran polémica en la literatura vinculada al estudio crítico de las religiones.

12 Guignebert, Charles: Manual de Historia Antigua del Cristianismo. 
varon distintas formas de la cruz al serle unido un travesaño Esta práctica surgió probablemente entre los fenicios, siendo adoptada por otros pueblos en la Antigüedad. Debido a su carácter cruel y vejatorio, los romanos la reservaron para ejecutar esclavos rebeldes y criminales, suplicio que no se aplicaba a los ciudadanos romanos, por estar muy por debajo de tal dignidad.

Lo que en otros tiempos fue cicuta, guadaña, hoguera, guillotina, silla eléctrica o fusil, alrededor del año 30 fue crucifixión. Constituía una manera de ejercer el control social y disciplinamiento mediante la tortura, como una forma de otorgar al desviado de la norma un castigo ejemplar -el suplicio-. Siendo una práctica sancionadora, la crucifixión tiene un carácter cruel, que busca exponer el dolor de una víctima a la comunidad como medida ejemplificadora para las buenas conductas.

Desde su dimensión simbólica, en tanto, la cruz no es en absoluto exclusiva del cristianismo. Existen otras culturas que ya habían imaginado antes la cruz, adoptándola como una imagen plena de significado. En la Antigüedad, ésta era conocida entre muchos pueblos, por ejemplo, el dios Anu, de los caldeo-babilónicos era simbolizado mediante una cruz de brazos iguales; los egipcios veían en la cruz un signo de inmortalidad, probablemente; el cetro del Apolo griego tenía la forma de una cruz, así como el martillo de Thor, propio de los escandinavos. En la India, la svástica es símbolo del principio masculino.

El hombre, en términos de Cassirer, es un animal simbólico: representa y se representa a sí mismo la realidad. Desde las últimas discusiones sobre el conocimiento, parece ser que el hombre jamás percibe la realidad de manera directa, con lo que el concepto mismo de realidad objetiva estalla, se hace insostenible. El mundo percibido por el hombre deviene representación, adquiriendo el símbolo la potencia de mediador entre el hombre y su universo sensorial. De acuerdo a Fromm, lo fundamental en los símbolos universales es precisamente la relación entre el símbolo y aquello que éste representa.

Resulta interesante preguntarse cómo la cruz histórica es adoptada como símbolo (lenguaje basado fundamentalmente en imágenes y emociones) ${ }^{13}$ del mundo cristiano y socializada como emblema de un mensaje religioso.

La cruz, como símbolo, es siempre más que sí misma: es el conjunto de significados asociados, los dogmas que han asumido -en este caso- los diversos cristianismos. La cruz en su uso social (como objeto: crucifijo, ícono, imagen lírica, etc.) es una señal de distinción que conforma los límites de una comunidad, un nosotros social, por tanto define trayectorias, un ethos $y$ un pathos, un conjunto de lugares asociados y ritos.

13 Cirlot, Juan Eduardo: "Diccionario de Símbolos". 


\section{La construcción simbólica de la cruz: la selección de un mensaje}

A partir del año 30 d.c $^{14}$ la cruz asume diversas representaciones y usos: el crucifijo se transforma incluso en un objeto estético, decorativo, utilizado de manera ornamental (aunque no sólo ornamental, por supuesto).

Podemos pensar que una vez leído bajo el registro de los cristianismos, es decir, una vez reconocido y absorbido como texto por la cultura, el crucifijo -o cualquier forma de reproducción de la cruz- es una de las marcas más potentes en cuanto tales del mundo occidental: ha sido extraordinariamente efectiva en la configuración de una comunidad.

Nuestra atención sobre la adopción simbólica de la cruz se funda en la constatación de su uso histórico como instrumento de control social. Desde una lógica interior al relato judeocristiano es posible entender la crucifixión como un sacrificio en pos de una purificación que viene a responder a la Caída del hombre (la expulsión del Paraíso). En dicho relato, la crucifixión de su Mesías es entendida como la consagración de su misión. Una vez que ha sido crucificado puede ser nombrado Salvador, puesto que redime al hombre de su caída, restableciendo una nueva alianza. Aquí podemos acudir a la lectura simbólica del sacrificio: alguna culpa ha sido expiada por medio de la consagración sacrificial, generando un intercambio de bienes de la comunidad con la divinidad. Desde nuestra lectura, podemos entender esta ofrenda como parte de un texto cultural, dirigida a un dios que ha sido imaginado como celoso, que tiende a poner a prueba a los hombres, demandándoles obediencia. En este caso, esta ofrenda es también un chivo expiatorio. Nos preguntamos $\underset{̨}{E}$ El sacrificio es condición del propio texto religioso judeocristiano, siendo la consumación del mito su expiación?

Si bien responder esto pertenece al campo de la teología, llama la atención -por decir lo menos- la vigencia de un mito que requiere hacer del sacrificio un emblema, al mismo tiempo que oculta su connotación histórica y visibiliza su carácter simbólico (transformándolo en algo parecido a una promesa: un pasaje a la Vida Eterna).

El planteamiento de Girard, sin embargo, nos conduce más allá: ¿̨Corresponde el sacrificio de un hombre a una necesidad epocal, como una práctica propia de la religiosidad primitiva que es reactualizada alrededor del año 30 ? La duda que surge frente a este planteamiento es ¿Por qué se recurre a un sacrificio en tiempos de Jesús? ¿No hubo antes y después situaciones socialmente más conflictivas entre el Imperio y el pueblo judío?

14 Queda aún por definir cuándo la cruz pasa a ser uno de los símbolos oficiales del cristianismo. Cabe presumir que es una de las estrategias que utiliza Constantino para socializar dicha religión. 
Independientemente de las respuestas que podamos dar a estas preguntas, podemos observar que lo que operará como uno de los principales capitales simbólicos del cristianismo será precisamente el acto sacrificial, lo que tendrá un especial papel en la construcción de un ciertos ethos cristiano. Paradójicamente, la víctima que fue sacrificada en la crucifixión es rescatada de su anonimato, proceso que va in crescendo con el paso del tiempo. Un tema que adquiere aquí especial connotación es el proceso de transfiguración de la cruz. Es decir, frente a la observancia de la víctima sacrificial se sublima su experiencia de tortura para ser transformado en un martirio santo: se escinde la víctima y se selecciona un mensaje. Una trágica muerte sentenciada a nombre de un Imperio es recordada como el más heroico de los pasajes bíblicos de la cristiandad.

\section{Bibliografía}

Bover, José María y Cantera, Francisco: "Sagrada Biblia. Versión Crítica sobre los textos hebreo y griego". Editorial católica, 1957, Madrid.

Cirlot, Juan Eduardo: “Diccionario de Símbolos”. Ediciones Siruela, 1977, Barcelona.

Girard, R: "La violencia y lo sagrado", Anagrama, 1983, Barcelona.

Girard, R: "El chivo expiatorio", Anagrama, 1986, Barcelona.

Guignebert, Charles: "Manual de Historia Antigua del Cristianismo", Editorial Albatros, 1945, Buenos Aires.

Van Der Leeuw, G: "Fenomenología de la Religión”, Fondo de cultura Económica, 1964, México.

Reinach, Salomón: “Orfeo. Historia de las Religiones”, Biblioteca nueva, Buenos Aires. 